\title{
Absence of cellular hypersensitivity to muscle and thymic antigens in myasthenia gravis ${ }^{1}$
}

\author{
WILHELMINA M. H. BEHAN, ${ }^{2}$ P. O. BEHAN, AND J. A. SIMPSON \\ From the University Departments of Pathology and Neurology, University of Glasgow
}

SYNOPSIS Humoral antibodies to skeletal muscle and its components and to thymus have been demonstrated in the sera of patients with myasthenia gravis. A role for cellular hypersensitivity to similar antigens in the pathogenesis of the disease has been suggested by some reports of the presence of cellular immunity. A detailed immunological study using muscle and thymic antigens, including those prepared from the patients' own tissues, failed to confirm these findings. It is suggested that previous reports of cellular hypersensitivity represent the demonstration of an epiphenomenon.

There is good evidence that immunological mechanisms are involved in the pathogenesis of myasthenia gravis (Simpson, 1960, 1975). The strongest argument is the fact that the thymus gland is histologically abnormal in more than $80 \%$ of cases; in about $70 \%$ medullary germinal centres are found and in about $10 \%$ a thymoma is present (Castleman and Norris, 1949). The proportion of patients in whom myasthenia is associated with a thymoma has been reported as from $10-30 \%$ of cases but the incidence increases with age and the overall percentage is therefore approximately $10 \%$ (Castleman, 1955 ; Simpson, 1958). Medullary germinal centres similar to those found in myasthenia are also seen in other disorders presumed to have an autohypersensitivity basis-for example, thyrotoxicosis and Addison's disease (Sloan, 1943), thyroiditis (Gunn et al., 1964), and systemic lupus erythematosus (Goldstein and Mackay, 1967). The centres have also, however, been seen in young normal subjects dying suddenly (Middleton, 1967) or undergoing cardiac surgery for congenital anomalies (Vetters and Barclay, 1973) and therefore their importance seems debatable (Vetters and Simpson, 1974).

There is a definite clinical association between myasthenia gravis and other presumed auto-

\footnotetext{
1 This work was supported by the Muscular Dystrophy Group of Great Britain.

2 Reprint requests to: W. M. H. Behan, Department of Pathology, Western Infirmary, Glasgow G11 6NT. (Accepted 9 May 1975.)
}

immune disorders-for example, rheumatoid arthritis (Simpson, 1960), systemic lupus erythematosus (Wolf and Barrows, 1966), Sjögren's disease (Brown et al., 1968), pernicious anaemia (Simpson, 1960, 1964; Bletcher and Williams, 1967), pemphigus (Beutner et al., 1968; Vetters et al., 1973), autoimmune haemolytic anaemia (Cohen and Waxman, 1967; Halperrin et al., 1966), Hashimoto's thyroiditis (Simpson, 1964), and thyrotoxicosis and hypothyroidism (Osserman et al., 1967; Simpson, 1968). Serological abnormalities including rheumatoid factor, antinuclear antibodies, thyroid and haemolytic autoantibodies have been frequently demonstrated in myasthenia (van der Geld et al., 1963; Adner et al., 1964; Simpson, 1964). Abnormalities in IgA metabolism have also been found in these patients (Behan et al., in preparation). Histologically, skeletal muscles from myasthenic patients show round cell infiltrates (lymphorrhages), non-specific findings which may suggest an immune response.

Humoral antibodies to skeletal muscle or its components have been demonstrated in the serum of myasthenic patients by a variety of techniques, including immunofluorescence (Strauss et al., 1965; Nastuk et al., 1966; Vetters, 1967), tanned red cell agglutination (Djanian et al., 1964), and precipitation in gels (Shulman et al., 1966). Strauss et al. (1965) originally demonstrated that the serum of $30 \%$ of myasthenics, and of almost all patients with myas- 
thenia gravis and a thymoma, contained antibody to muscle demonstrable on immunofluorescent staining. They used 900 control cases consisting of normal subjects and patients with a great variety of neurological disorders and showed that all but one were negative. Other workers have reported positive immunofluorescence in normal undiluted serum but Strauss used serum at a dilution of 1 in 60 and considered the reaction that he found was specific and characteristic of the disease.

The role of these antibodies in disease pathogenesis, however, is doubtful since antibodies are not present in the majority of patients with myasthenia and, even when present, there tends to be no correlation between the antibody titre and the course and severity of the disease (Oosterhuis et al., 1967). Mothers with myasthenia have been found to show high antibody titres with no symptomatology in the neonate and the reverse has been described (Oosterhuis et al., 1966). Again, patients with a thymoma often have high titres of anti-muscle antibody and yet show no evidence of myasthenia even on detailed electrophysiological testing (McFarlin et al., 1966). Theoretically, it is also difficult to account for a transmission defect produced by anti-muscle antibodies involving myofibrils rather than by a process which affects the motor end-plates.

The original suggestion of Simpson (1960) of a cell-mediated immunity in myasthenia gravis has, therefore, been reconsidered. Several reports have suggested that such mechanisms are involved but the results have been conflicting. It was decided to investigate cellular hypersensitivity to a variety of muscle and thymic antigens in myasthenia using a standardized and reproducible in vitro technique (Soborg and Bendixen, 1967; Rosenberg and David, 1970). These antigens were prepared similarly (1) to those used in other reports which had claimed positive cell mediated immune responses (Alpert et al., 1972; Armstrong et al., 1973; Kott et al., 1973; Goust et al., 1974), or those which had been claimed to induce an experimental thymitis and a partial neuromuscular block in guinea-pigs (Kalden et al., 1973), and (2) to those antigens which react specifically with the sera of patients with myasthenia (Aarli, 1972). In addition, control nonmuscle antigens were used to which the patients demonstrated delayed hypersensitivity by skin testing. Finally, a group of patients were tested immediately before and within a week after thymectomy with antigens prepared from their own thymus and skeletal muscle so as to obviate the possible effect of histocompatibility antigens.

\section{METHODS}

SUBJECTs Patients $A$ Fifteen patients with myasthenia gravis of varying stages of severity, none of whom had undergone thymectomy.

Patients $B$ Nine patients with myasthenia gravis who were tested before and after thymectomy.

Patients $C$ Thirty control subjects consisting of 10 normal subjects and 20 patients with a variety of neurological disorders affecting the central and peripheral nervous system: sciatica (five), peripheral neuropathy (two), meningioma (two), glioma (three), cerebrovascular haemorrhage (two), cerebrovascular thrombosis (four), subarachnoid haemorrhage (two).

ANTIGENS 1. Streptokinase/streptodornase

Vari- $\bigcirc$ O dase, Lederle Laboratories) (SKSD) This was used at a concentration of 300 units $/ \mathrm{ml}$ tissue culture fluid.

2. Muscle antigens Three categories of muscle antigens were prepared from skeletal muscle obtainedo at thymectomy, other operations, or necropsy and dissected as free as possible of connective tissue, fat, and blood. One of the five antigens listed below was then prepared.

a. Preparation of muscle homogenate Fresh muscle was placed in a sterile dish, diced with a scalpel blade, and then homogenized in phosphate buffered saline $\mathrm{pH} 7.2$, as a $20 \% \mathrm{w} / \mathrm{v}$ homogenate, in a Sorval Omnimix Blender. It was then centrifuged for 15 minutes at maximum speed and aliquots of the supernatant were stored at $-20^{\circ} \mathrm{C}$ and used within three weeks of preparation. Before use, the antigens were frozen and thawed once, then diluted with RPMI 1640 tissue culture fluid to obtain the desired dilution. Dose response curves were used initially to determine cytotoxicity of the antigen. The concentrations finally used were $1 / 100$ and $1 / 50$ dilutions of the original $20 \% \mathrm{w} / \mathrm{v}$ homogenate.

b. Preparation of soluble and microsomal fractions of muscle The method of Kalden et al. (1973) was followed. Fresh skeletal muscle tissue was homogenized $(20 \% \mathrm{w} / \mathrm{v})$ in phosphate buffered saline 
$\mathrm{pH}$ 7.2. The homogenate was centrifuged for 10 minutes at $2500 \mathrm{~g}$ and the supernatant then used to prepare the fractions needed. First the supernatant was centrifuged for 30 minutes at $10000 \mathrm{~g}$ at $4^{\circ} \mathrm{C}$. The sediment was discarded and the supernatant further centrifuged in a Beckman vacuum ultracentrifuge at $105000 \mathrm{~g}$ for one hour. The final sediment obtained (so-called microsomal fraction) and the supernatant (so-called soluble fraction) were lyophilized. The lyophilized fractions were prepared for use by dissolving in RPMI 1640 tissue culture fluid and making up to concentrations of $500 \mu \mathrm{g} / \mathrm{ml}$ (microsomal fraction) and $500 \mu \mathrm{g} / \mathrm{ml}$ and $250 \mu \mathrm{g} / \mathrm{ml}$ (soluble fraction). These concentrations were determined to be non-cytotoxic by previous dose-response measurements.

c. Preparation of citric acid extract of muscle Skeletal muscle was thawed, minced, and washed in cold phosphate buffered saline repeatedly until the supernatant was free of all discoloration. A citric acid extract was then prepared as described by Espinosa and Kaplan (1968) and used by Aarli (1972). The procedure included repeated extractions with $0.85 \%$ $\mathrm{NaCl}$ before treatment with $0.05 \mathrm{M}$ citric acid. The final extract obtained was lyophilized. It was easily soluble in RPMI 1640 and concentration response curves were used in order to obtain a concentration of the extract which did not produce non-specific inhibition in the controls. In most cases the concentration used was $50 \mu \mathrm{g} / \mathrm{ml}$.

3. Thymus antigens Human thymus obtained at operation for thymectomy was dissected free of connective tissue, fat, and blood vessels. It was washed repeatedly in cold phosphate buffered saline and then frozen to $-20^{\circ} \mathrm{C}$ unless used at once to prepare the antigens.

a. Preparation of thymus homogenate Fresh thymus tissue was minced, then homogenized in $20 \% \mathrm{w} / \mathrm{v}$ in RPMI 1640 using a Sorval Omnimix blender. It was filtered once through cotton gauze and then frozen and thawed once before being stored at $-20^{\circ} \mathrm{C}$ until use. It was used at a final concentration of $1 / 20$ of the original $20 \% \mathrm{w} / \mathrm{v}$ homogenate.

b. Preparation of thymus soluble antigen The method of Goust et al. (1974) was used. Fresh thymus was minced and suspended in $10 \% \mathrm{w} / \mathrm{v}$ in $0.5 \mathrm{M}$ saline and then homogenized in a Sorval Omnimix blender at maximum speed in bursts of 20 seconds. The homogenate was then spun at $1000 \mathrm{~g}$ for 15 minutes and the lipid-free supernatant lyophilized. The above operations were all carried out at $4^{\circ} \mathrm{C}$. Finally, protein concentration was adjusted to give a final concentration of $100 \mu \mathrm{g} / \mathrm{ml}$.

SKIN TESTING Patients and control subjects were skin tested by an intradermal injection into the volar surface of the arm of $0.1 \mathrm{ml}$ of a normal saline solution containing 5 units and, if unreactive to this, a saline solution containing 10 units of streptokinase/ streptodornase. The results were examined at 24 and 48 hours and were considered to be positive when the raised indurated area was greater than $1.0 \mathrm{~cm}$ in diameter.

In vitro TECHNIQUE OF MACROPHAGE INHIBITION The leucocyte migration test was performed according to the technique of Soborg and Bendixen (1967) with modifications as indicated. Essentially $50 \mathrm{ml}$ venous blood was taken under sterile conditions into a syringe containing 1000 units of preservative-free heparin and $10 \mathrm{ml}$ dextran. The blood was then allowed to sediment at $37^{\circ} \mathrm{C}$ for 20 minutes. All but the bottom $0.5 \mathrm{~cm}$ of leucocyte-rich plasma was removed and the suspension then centrifuged at $250 \mathrm{~g}$ for 10 minutes. Nine volumes of $0.83 \%$ ammonium chloride were added and the cells resuspended and left in this solution for four minutes exactly. (The ammonium chloride lysed the red cells present.) The cells were then centrifuged at $200 \mathrm{~g}$ and washed twice in RPMI 1640 tissue culture fluid and then once in RPMI 1640 to which $10 \%$ fetal calf serum had been added and $1.0 \%$ penicillin and streptomycin. After the final wash the cell pellet was suspended in the residual fluid and a trial capillary filled and sealed with Critoseal. This capillary was centrifuged at $200 \mathrm{~g}$ for four minutes and the concentration of the cell suspension remaining was adjusted so that after dilution with antigen ( $1 / 5$ dilution) a length of $2-3 \mathrm{~mm}$ of the capillary would be filled with packed cells. Usually between 2.2 and $2.8 \mathrm{ml}$ of cell suspension of the required concentration was obtained, meaning that a total of between 22 and 28 chambers (each containing two capillaries) could be set up. The cell suspension was then divided into at least nine aliquots of $0.2 \mathrm{ml}$. Each aliquot was incubated with $0.05 \mathrm{ml}$ of one of the various antigens (and one aliquot had $0.05 \mathrm{ml}$ of RPMI 1640 alone added) for two hours at $37^{\circ} \mathrm{C}$. Thus a minimum of two chambers was set up for each antigen and the controls. If the number of cells permitted, the aliquots of each cell suspension and the antigen were increased accordingly. At the end of the two hour incubation period haematocrit tubes were filled with the cell suspensions sealed at one end with Critoseal and centrifuged at $200 \mathrm{~g}$ for four minutes. The tubes were cut at the cell-fluid interphase and the cell bearing ends of two capillaries placed in each small culture chamber 
(planchette: Univers, Meckaniska, Sweden) secured at one end with silicone grease (Dow Corning, vacuum silicone grease). The chambers were filled with tissue culture medium RPMI 1640, sealed with a greased cover slip, and incubated for 18 hours at $37^{\circ} \mathrm{C}$. The migration surfaces were then examined under a Leitz Diavert inverted microscope with drawing attachment and the area of migration drawn on white paper. This area was measured with a planimeter. The migration index was then calculated thus:

migration index

$$
=\frac{\text { surface area in presence of antigen }}{\text { surface area in absence of antigen }} \times 100
$$

Each result is the average of at least four capillary measurements: unless the measurements agreed within $15 \%$ the result was discarded. An inhibition of migration of more than $30 \%$ was considered to be a significant result.

AUtologous ANTIGeNS Group B patients were tested for possible cell-mediated immunity to their own muscle and thymus. Their peripheral blood was withdrawn before thymectomy and set up as described in the presence of crude homogenates of muscle and thymus obtained at operation. The experiment was repeated one week later using the same antigens.

\section{RESULTS}

Delayed hypersensitivity, as demonstrated by inhibition of macrophage migration greater than $30 \%$, was observed in all patients tested with the SKSD antigen. Excellent correlation was observed between this finding in vitro and the demonstration of cutaneous reactivity to SKSD with thickened, indurated lesions greater than $1.0 \mathrm{~cm}$ in vivo.

No inhibition of any significant degree (greater than $30 \%$ ) could be found in normal subjects or in the three groups of patients, to any of the antigens prepared from thymus and muscle (Figs 1, 2, and 3).

It can be seen that thymectomy had no influence on the results of testing with SKSD antigens, as measured in vitro. Similarly, thymectomy did not influence the negative results to muscle and thymic antigens in the patients tested with autologous antigens before and after operation.

\section{DISCUSSION}

We were able to demonstrate that the in vitro technique of macrophage migration inhibition 


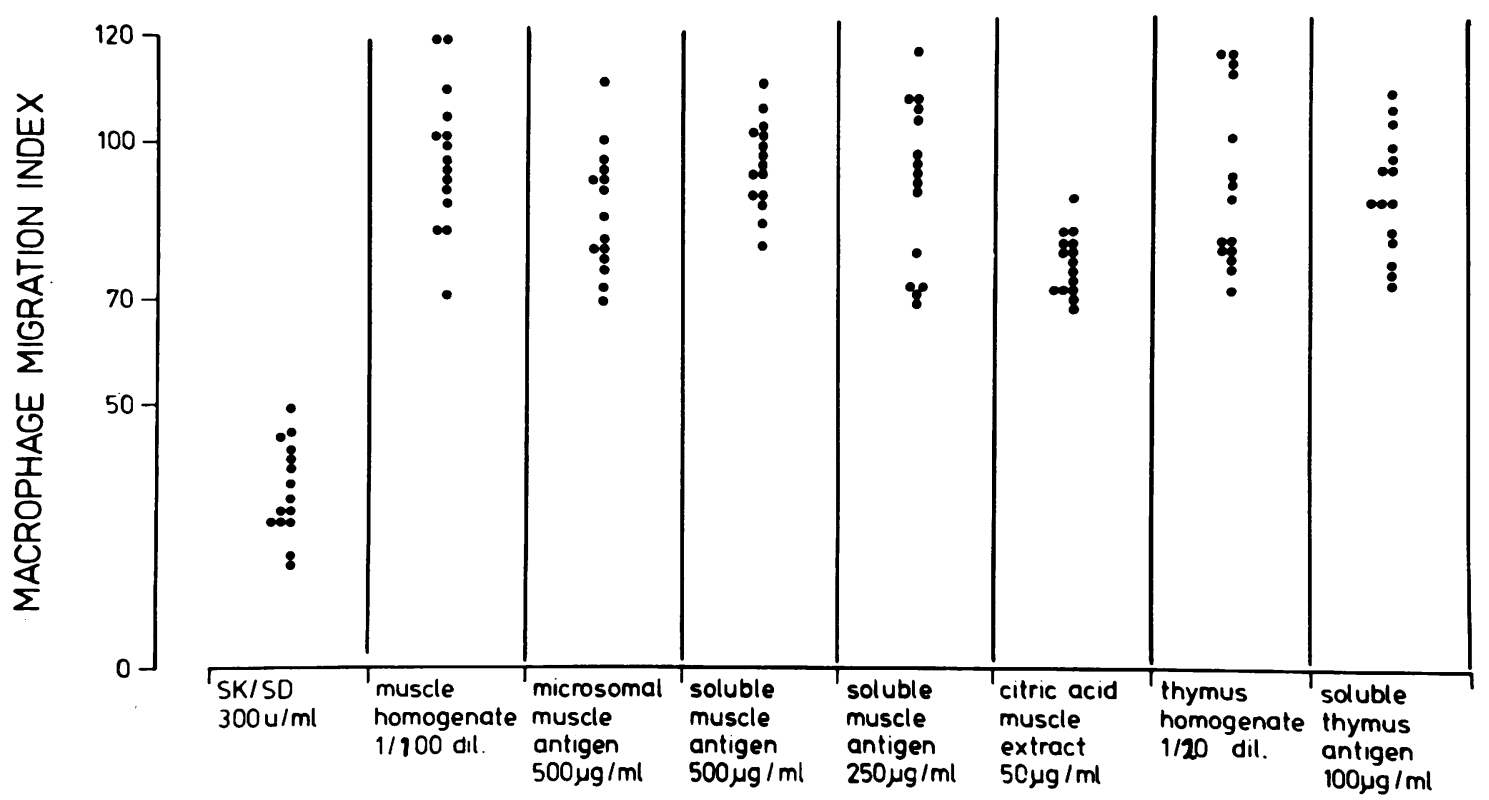

ANTIGENS

FIG. 2 Migration Index of peripheral blood leucocytes on contact with muscle and thymic antigens, in 15 nonthymectomized patients with myasthenia gravis.

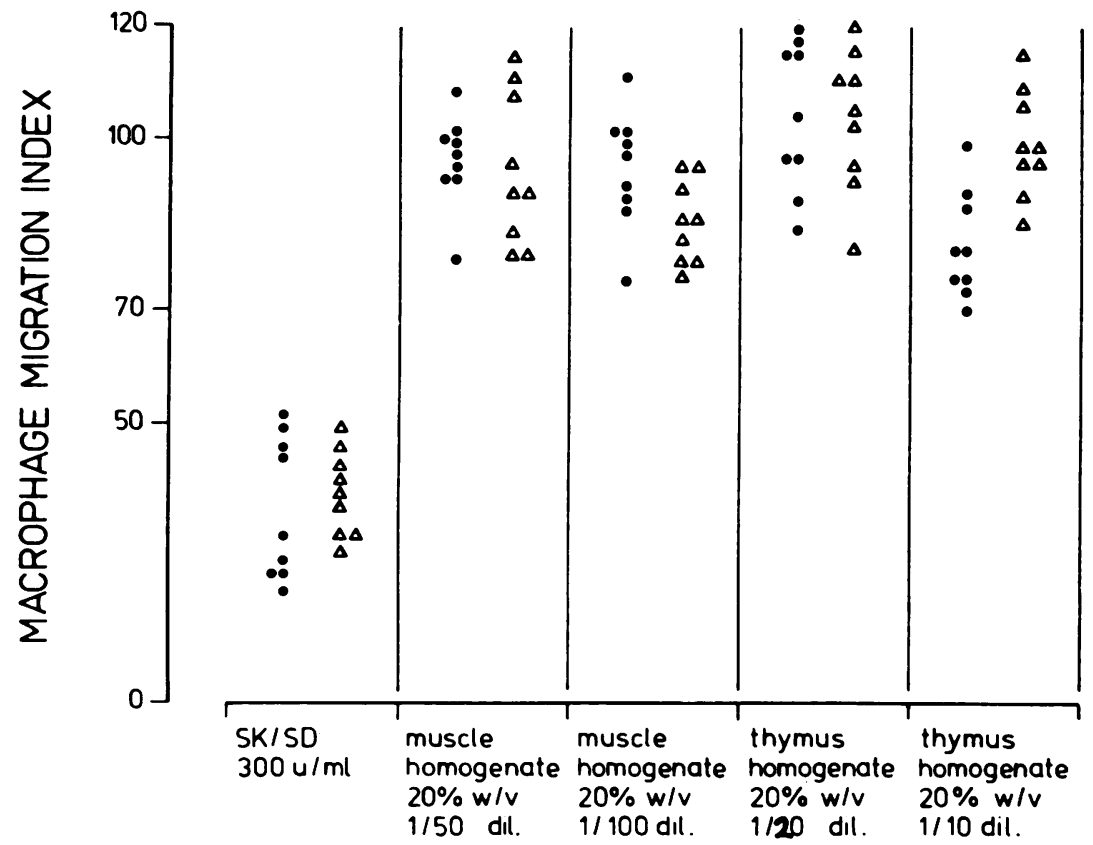

FIG. 3 Migration Index of peripheral blood leucocytes on contact with muscle and thymic antigens, in nine patients with myasthenia gravis, before and after thymectomy. $=$ before thymectomy. $\triangle=$ after thymectomy.

\section{ANTIGENS}


detected cell-mediated immunity to streptokinase/ streptodornase (SKSD) but we were unable to show similar sensitivity to any of the skeletal muscle or thymic antigens employed in our experimental subjects. These results, therefore, conflict with those of other workers who, using the same technique, claim to have found hypersensitivity to muscle and thymic antigens in patients with myasthenia.

Alpert et al. (1972) obtained positive inhibitory responses to crude skeletal muscle and myosincontaining fractions in 14 of 21 myasthenics. They considered inhibition of migration of more than $30 \%$ to be significant: 12 of their patients showed this degree of inhibition but inhibition to the same antigens of up to $10 \%$ was also present in their control subjects. No positive control antigens were used in the system-for example, PPD, candida, or SKSD but with nonspecific proteins, such as meconium extract, they obtained greater than $20 \%$ migration inhibition in some patients. A strong positive correlation was noted between the degree of cell-mediated immunity and the titre of humoral muscle antibodies.

Armstrong et al. (1973), using thymic lymphocytes, found cellular hypersensitivity to crude muscle and crude thymus antigens in myasthenic patients but also reported similar sensitivity to muscle in nearly $50 \%$ of their control subjects. In addition, they obtained a positive response in a patient with a thymoma who did not have myasthenia gravis. Kott et al. (1973) showed positive in vitro responses to crude muscle and myosin-containing fractions as antigen in $63 \%$ of their patients with myasthenia gravis. They noted, however, poor correlation between cellmediated immunity and the presence of humoral antibodies but they were able to demonstrate a correlation between the stage of the disease and cell-mediated or humoral immunity. The authors stated that tuberculin was used as a positive control antigen but these particular results were not presented.

Goust et al. (1974) found cell-mediated immunity to muscle and thymic antigens in 45 of their 46 patients. They used monkey muscle and thymus and human muscle as antigens. They demonstrated that some of their patients responded only to human muscle and others only to monkey muscle and one to monkey thymus only. They noted that 'no correlation appears to exist between the clinical and pathological data' and presence of a thymoma, thymectomy, or a changing clinical state did not influence the results of their test. No control antigens of any sort were used and some of their control subjects had inhibition of $20-35 \%$ to the muscle and thymus used as antigen. Positive responses to the muscle extracts were also found in 12 of 14 patients with polymyositis but without myasthenia gravis.

A criticism that can be made of all these reports is that positive control antigens were not used. In addition, dose response curves were not employed to measure cellular hypersensitivity when present. In our experiments, increasing the dose of antigen had no effect, whereas if sensitivity were present one would expect some increase of inhibition with an increase in antigen concentration. Furthermore, Goust et al. (1974) noted that enhancement of macrophage migration was present in 10 cases at one or both of $\overrightarrow{0} \overrightarrow{0}$ the antigen concentrations used and they stated $\stackrel{\vec{\Phi}}{\vec{D}} \underset{0}{ }$ that 'in myasthenia gravis, with this technique, $\frac{\rho}{1}$ 음 an augmentation of the migration index seems $0 \rightarrow$ as significant as a depression'. Augmentation is $z$ found in the macrophage migration inhibition 8 test when no sensitivity exists, so that this statement is open to criticism.

A non-specific inhibition of macrophage migra- $\stackrel{\vec{\ominus}}{\vec{\theta}}$ tion may occur due to differing histocompatibility antigens. Falk et al. (1970) showed that non-sensitized lymphocytes were stimulated to produce macrophage inhibiting factor on contact with different histocompatibility antigens. We used autologous antigens in some of our experiments in order to eliminate this effect but the phenomenon may help to explain, in part, the inhibition noted by other workers.

Our findings do agree with those of experimenters who used different in vitro methods to try to detect cell-mediated immunity to muscle and thymic antigens in patients with myasthenia gravis. Houseley and Oppenheim(1967)and Lisak and Zweiman (1975), employing the technique of measuring lymphocyte proliferative responses, were unable to show any sensitivity in patients with myasthenia. Similarly, Abramsky et al. (1975), using a lymphocyte transformation method, found no response to crude muscle antigen in the myasthenic patients they investigated. 
The inhibition which has been observed is most likely an epiphenomenon. Indeed, Alpert et al. (1972) point out in the interpretation of their results that the findings need not reflect a primary immunological effect but rather 'may simply reflect a cellular response to tissue alteration resulting from another cause'. This was also the opinion of Lisak and Zweiman (1975) who stated 'it would be somewhat surprising if such reactivity (cell-mediated immunity) was pathogenic in the face of the disparate clinical features of the two disorders' (the other condition they referred to was polymyositis in which cellmediated immunity has been shown by Currie et al. 1971).

The specificity and significance of cell-mediated immune responses to muscle in myasthenia gravis is questioned because of the demonstration of similar sensitivity in patients with muscular dystrophy (Caspary et al., 1971), polymyalgia rheumatica (Esiri et al., 1973), and Guillain-Barré syndrome (Caspary et al., 1971). Furthermore, Kott et al. (1971) have reported sensitivity to central nervous system antigens in patients with myasthenia gravis and Caspary et al. (1971) have found similar reactivity to these same antigens in patients with muscular dystrophy.

The possibility that muscle and thymic antigens might be involved in the pathogenesis of myasthenia gravis, however, is also suggested by the work of Goldstein and Whittingham (1966) and Kalden and Irvine (1969) who claim that myasthenia gravis can be produced in guineapigs by immunizing them with these antigens. Several other investigators, however, have been unable to confirm their findings (Kaufmann et al., 1969; Namba and Grob, 1969; Vetters et al., 1969; Behan, 1974). None of the animals immunized by the former workers developed clinical disease and subtle electrophysiological changes were used as the criteria for diagnosis of myasthenia. These changes are non-specific and open to differing interpretations (Vetters et al., 1969; Brooks, 1971). The antigens used by Kalden et al. (1973) failed to elicit any positive responses in our system.

The occurrence of myasthenia gravis in association with diseases in which there is anergyfor example, chronic lymphatic leukaemia (Cohen and Waxman, 1967), lymphosarcoma (Simpson, 1960), Hodgkin's disease, systemic lupus erythematosus (Wolf and Barrows, 1966), and sarcoidosis (Simpson, 1960; 1964)-militates against cell-mediated hypersensitivity being involved in the pathogenesis of the disease. Fudenberg (1971) has postulated that there is a depression of T-cell function rather than a hyperallergic state in the autoimmune disorders. In fact, myasthenic patients show impaired immune responses to dinitrochlorobenzene(DNCB) sensitization (Adner et al., 1964).

An association between certain histocompatibility antigens and myasthenia has also been demonstrated recently (Pirskanen et al., 1972; Behan et al., 1973). HLA-8 has been found to occur with a very high frequency in myasthenia gravis, gluten enteropathy, dermatitis herpetiformis, and autoimmune thyroiditis (Dausset et al., 1974). It is claimed that HLA-8 is associated with disorders of impaired immunity (Da Costa et al., 1974).

Our work, therefore, provides no evidence to support the theory that cell-mediated immunity to muscle or thymic antigens is involved in the pathogenesis of myasthenia gravis. The most likely explanation for the previous reports of such cellular hypersensitivity is that these findings represent an epiphenomenon and not true cellmediated immunity.

The encouragement and advice of Professor J. R. Anderson are gratefully acknowledged.

\section{REFERENCES}

Aarli, J. A. (1972). Myasthenia gravis. Antibodies to an acid-soluble antigen in striated muscle. Clinical and Experimental Immunology, 10, 453-461.

Abramsky, O., Aharonov, A., Webb, C., and Fuchs, S. (1975). Cellular immune response to acetylcholine receptor rich fraction in patients with myasthenia gravis. Clinical and Experimental Immunology, 19, 11-16.

Adner, M. M., Sherman, J. D., Ise, C., Schwab, R. S., and Dameshek, W. (1964). An immunologic survey of fortyeight patients with myasthenia gravis. New England Journal of Medicine, 271, 1327-1333.

Alpert, L. I., Rule, A., Norio, M., Kott, E., Kornfeld, P., and Osserman, K. E. (1972). Studies in myasthenia gravis: cellular hypersensitivity to skeletal muscle. American Journal of Clinical Pathology, 58, 647-653.

Armstrong, R. M., Novak, R. M., and Falk, R. E. (1973). Thymic lymphocyte function in myasthenia gravis. Neurology (Minneap.), 23, 1078-1083.

Behan, P. O. (1974). Myasthenia gravis and thymic disease. In Progress in Immunology II, vol. 5, p. 312. Edited by L. Brent and J. Holborrow. North Holland: Amsterdam.

Behan, P. O., Simpson, J. A., and Dick, H. (1973). Immune response genes in myasthenia gravis. Lancet, $2,1033$. 
Beutner, E. H., Chorzelski, T. P., Hale, W. L., and Hausmanowa-Petrusewicz, I. (1968). Autoimmunity in concurrent myasthenia gravis and pemphigus erythematosus. Journal of the American Medical Association, 203, 845-849.

Bletcher, T. E., and Williams, E. R. (1967). Simultaneous myasthenia gravis and pernicious anaemia. A case report with organ antibody studies. Postgraduate Medical Journal, 43, 122-126.

Brooks, J. (1971). Experimental myasthenia gravis. Research Publications. Association for Research in Nervous and Mental Diseases, 49, 253-257.

Brown, J. W., Nelson, J. R., and Hermann, C. Jr (1968). Sjogren's syndrome with myopathic and myasthenic features. Bulletin of the Los Angeles Neurological Society, 33, 9-20.

Caspary, E. A., Currie, S., and Field, E. J. (1971). Sensitised lymphocytes in muscular dystrophy: evidence for a neural factor in pathogenesis. Journal of Neurology, Neurosurgery, and Psychiatry, 34, 353-356.

Caspary, E. A., Currie, S., Walton, J. N., and Field, E. J. (1971). Lymphocyte sensitization to nervous tissue and muscle in patients with the Guillain-Barré syndrome. Journal of Neurology, Neurosurgery, and Psychiatry, 34, 179-181.

Castleman, B. (1955). Tumors of the Thymus Gland. Armed Forces Institute of Pathology. Section 5, Fasciscle 19. National Research Council: Washington, D.C.

Castleman, B., and Norris, E. H. (1949). Pathology of thymus in myasthenia gravis. Medicine (Balt.), 28, 27-58.

Cohen, S. M., and Waxman, S. (1967). Myasthenia gravis, chronic lymphocytic leukemia and autoimmune hemolytic anemia. Archives of Internal Medicine, 110, 717-720.

Currie, S., Saunders, M., Knowles, M., and Brown, A. E (1971). Immunological aspects of polymyositis: the in vitro activity of lymphocytes on incubation with muscle antigen and with muscle culture. Quarterly Journal of Medicine, 40, 63-84.

Da Costa, J. A. G., White, A. G., and Parker, A. C. (1974). Increased incidence of HL-A 1 and 8 in patients showing IgG or complement coating on their red cells. Journal of Clinical Pathology, 27, 353-355.

Dausset, J., Degos, L., and Hors, J. (1974). A review: the association of the HL-A antigens with disease. Clinical Immunology and Immunopathology, 3, 127-149.

Djanian, A. W., Beutner, E. H., and Witebsky, E. (1964). Tanned-cell haemagglutination test for detection of antibodies in sera of patients with myasthenia gravis. Journal of Laboratory and Clinical Medicine, 63, 60-70.

Esiri, M. M., MacLennan, I. C. M., and Hazleman, B. L. (1973). Lymphocyte sensitivity to skeletal muscle in patients with polymyositis and other disorders. Clinical and Experimental Immunology, 14, 25-35.

Espinosa, E., and Kaplan, M. H. (1968). Antigenic analysis of human heart tissue. Journal of Immunology, 100, 10201031.

Falk, R. E., Thorsby, E., Möller, E., and Möller, G. (1970). In vitro assay of CMI : the inhibition of migration of sensitised human lymphocytes by HL-A antigens. Clinical and Experimental Immunology, 6, 445-455.

Fudenberg, H. H. (1971). Are autoimmune diseases immunologic deficiency states? In Immunobiology, pp. 175-183. Sinauer Associates: Stamford, Connecticut.

Geld, H. van der, Feltkamp, T. E. W., Loghem, J. J. van, Oosterhuis, H. J. G. H., and Biemond, A. (1963). Multiple antibody production in myasthenia gravis. Lancet, 2,373 375.

Goldstein, G., and Mackay, I. R. (1967). The thymus in systemic lupus erythematosus: a quantitative histo- pathological analysis and comparison with stress involution. British Medical Journal, 2, 475-478.

Goldstein, G., and Whittingham, S. (1966). Experimental autoimmune thymitis: an animal model of human myasthenia gravis. Lancet, 2, 315-318.

Goust, J. M., Castaigne, A., and Moulais, R. (1974). Delayed hypersensitivity to muscle and thymus in myasthenia gravis and polymyositis. Clinical and Experimental Immunology, 18, 39-47.

Gunn, A., Michie, W., and Irvine, W. J. (1964). The thymus in thyroid disease. Lancet, 2, 776-777.

Halperrin, I. C., Minogue, W. F., and Komninos, Z. D. (1966). Autoimmune hemolytic anemia and myasthenia gravis associated with a thymoma. New England Journal of Medicine, 275, 663-664.

Houseley, J., and Oppenheim, J. J. (1967). Lymphocyte transformation in thymectomised and non-thymectomised patients with myasthenia gravis. British Medical Journal, 2, 679-681.

Kalden, J. R., and Irvine, W. J. (1969). Experimental myasthenia gravis. Lancet, $2,638$.

Kalden, J. R., Williamson, W. G., and Irvine, W. J. (1973). Experimental myasthenia gravis, myositis and myocarditis in guinea pigs immunised with subcellular fractions of calf thymus or calf skeletal muscle in Freund's adjuvant. Clinical and Experimental Immunology, 13, 79-88.

Kaufmann, B. M., Rushworth, G., and Wright, R. (1969). Experimental studies related to autoimmunity in myasthenia gravis. Journal of Neurology, Neurosurgery, and Psychiatry, 40, 281-289.

Kott, E., Genkins, G., and Rule, A. H. (1973). Leukocyte response to muscle antigens in myasthenia gravis. Neurology (Minneap.), 23, 374-380.

Kott, E., Osserman, K. E., and Rule, A. H. (1971). Myasthenia gravis: migration inhibition of leucocytes in the presence of central nervous tissue antigens and muscle antigens. Lancet, 2, 816-818.

Lisak, R. P., and Zweiman, B. (1975). Mitogen and muscle extract induced in vitro proliferative responses in myasthenia gravis, dermatomyositis and polymyositis. Journal of Neurology, Neurosurgery, and Psychiatry, 38, 521-524.

McFarlin, D. E., Barlow, M., and Strauss, A. J. L. (1966). Antibodies to muscle and thymus in non-myasthenia patients with thymoma. New England Journal of Medicine, 275, 1321-1326.

Middleton, G. (1967). The incidence of follicular structures in the human thymus at autopsy. Australian Journal of Experimental Biology and Medical Science, 45, 189-199.

Namba, T., and Grob, D. (1969). Effect of antibodies against skeletal muscle constituents on muscle function in rats. Revue Canadienne de Biologie, 28, 9-18.

Nastuk, W. L., Kessler, H. J., Grynbaum, A., Smith, M., and Hermann, C. Jr (1966). Immunological changes following thymectomy in myasthenia gravis. Archives of Neurology (Chic.), 15, 1-12.

Oosterhuis, H. J. G. H., Feltkamp, T. E. W., and Geld, H. R. W. van der (1966). Muscle antibodies in myasthenic mothers and their babies. Lancet, 2, 1226-1227.

Oosterhuis, H. J. G. H., Geld, H. R. W. van der, and Feltkamp, T. E. W. (1967). Studies in myasthenia gravis, part 2. The relation of some clinical and immunological data. Journal of the Neurological Sciences, 4, 417-434.

Osserman, K. E., Tsairis, P., and Weiner, L. B. (1967). Myasthenia gravis and thyroid disease: clinical and immunological correlation. Journal of the Mount Sinai Hospital, 34, 469-483.

Pirskanen, R., Tillikainen, A., and Hokkanen, B. (1972). Histocompatibility (HL-A) antigens associated with myasthenia gravis. A preliminary report. Annals of Clinical Research, 4, 304-306. 
Rosenberg, S. A., and David, J. R. (1970). Inhibition of leucocyte migration: an evaluation of this in vitro assay of delayed hypersensitivity in man to a soluble antigen. Journal of Immunology, 105, 1447-1452.

Shulman, S., Lang, R., Beutner, E., and Witebsky, E. (1966). Precipitation of autoantibody in serum from patients with myasthenia gravis. Immunology, 10, 289-303.

Simpson, J. A. (1958). An evaluation of thymectomy in myasthenia gravis. Brain, 81, 112-144.

Simpson, J. A. (1960). Myasthenia gravis. A new hypothesis. Scottish Medical Journal, 5, 419-436.

Simpson, J. A. (1964). Immunological disturbances in myasthenia gravis with a report of Hashimoto's disease developing after thymectomy. Journal of Neurology, Neurosurgery, and Psychiatry, 27, 485-492.

Simpson, J. A. (1968). The correlations between myasthenia gravis and disorders of the thyroid gland. In Research in Muscular Dystrophy, pp. 31-41. Proceedings of the IV Symposium, January, 1968. Pitman: London.

Simpson, J. A. (1975). Tolleranza immunologica e miastenia. Il ruolo del timo nell' accrescimento e nella differenziazione. (In press.)

Sloan, H. E., Jr (1943). The thymus in myasthenia gravis. Surgery, 13, 154-174.
Soborg, M., and Bendixen, G. (1967). Human lymphocyte migration as a parameter of hypersensitivity. Acta Medica Scandinavica, 181, 247-256.

Strauss, A. J. L., Geld, H. W. R. van der, Kemp, P. G., Jr, Exum, E. D., and Goodman, H. O. (1965). Immunological concomitants of myasthenia gravis. Annals of the New York Academy of Sciences, 124, 744-766.

Vetters, J. M. (1967). Muscle antibodies in myasthenia gravis. Immunology, 13, 275-280.

Vetters, J. M., and Barclay, R. S. (1973). The incidence of germinal centres in thymus glands of patients with congenital heart disease. Journal of Clinical Pathology, 26, 583-591.

Vetters, J. M., Saikia, N. K., Wood, J., and Simpson, J. A. (1973) Pemphigus vulgaris and myasthenia gravis. British Journal of Dermatology, 88, 437-441.

Vetters, J. M., and Simpson, J. A. (1974). Comparison of thymic histology with response to thymectomy in myasthenia gravis. Journal of Neurology, Neurosurgery, and Psychiatry, 37, 1139-1145.

Vetters, J. M., Simpson, J. A., and Folkarde, A. (1969). Experimental myasthenia gravis. Lancet, 2, 28-31.

Wolf, S. M., and Barrows, H. S. (1966). Myasthenia gravis and systemic lupus erythematosus. Archives of Neurology (Chic.), 14, 254-258. 